\title{
Community-Relevant Research for TCC STEM Student Retention
}

\section{Ms. Audrey Lynn LaVallie, Turtle Mountain Community College}

A. LaVallie, M.S., is a chemistry instructor at Turtle Mountain Community College in Belcourt, ND. She has directed various grant programs at TMCC, aimed at providing STEM research opportunities for Native American students, funded variously by the CDC, NSF, NASA, and EPSCoR.

\section{Dr. Eric Asa, North Dakota State University}

Dr. Eric Asa is an Associate Professor in the Department of Construction Management and Engineering at North Dakota State University, Fargo, North Dakota. He holds a doctoral degree in Civil and Environmental Degree from the University of Alberta. His research interests are the application of spatial statistical, computational and intelligent algorithms to civil/construction engineering problems, sustainable construction and infrastructure and STEM education of minorities.

\section{Dr. G. Padmanabhan P.E., North Dakota State University}

G. Padmanabhan, Ph. D., P.E., M. ASEE, F. ASCE is a professor of civil engineering at North Dakota State University, Fargo, North Dakota. He is a long standing member of ASEE. He also serves as the Director of North Dakota Water Resources Research Institute. He has been active in STEM education outreach activities to Native American students at the college and high and middle school levels for the last twelve years. His outreach activities have been supported by funds from the NSF, NASA, and Office of Naval Research. 


\section{Community-Relevant Research for TCC STEM Student Retention}

\section{Introduction}

Community colleges in the United States are currently experiencing greatly increased enrollment (17\% from 2007 to 2009$)^{1}$ and, although traditionally concerned with two-year undergraduate education, have become the focus of programs which encourage research as a means of retaining and developing students who have chosen scientific fields as career choices. Historically, undergraduate research has not always been considered to be important or even practical, but in the wake of educational research showing that authentic, inquiry-based projects help students improve in math /science skills and also help students to maintain interest in science fields ${ }^{2,3,4}$. Many broad-based funding agencies such as the National Science Foundation (NSF) and National Atmospheric and Space Agency (NASA) have found it germane to fund programs aimed at providing STEM-based research at earlier stages in students' education. Indeed, over the past 15 years, many graduate programs have come to expect undergraduate applicants to have some experience in undergraduate research; a lack of research experience can negatively impact applicant success 5 .

Most of the high school students on the North Dakota Reservations aspiring to pursue careers in STEM areas are likely to enroll in the Tribally Controlled Colleges (TCCs) first and then move on to four-year universities. The TCCs continue to make great strides toward improving the lives of their members on the Reservation by creating culturally sensitive educational opportunities. However, there was concern with the low enrolment in STEM courses and programs. In order for this situation to improve, programs had to be developed which not only motivate students to pursue college education in STEM, but also help guide them through graduation. A core group of faculty from the two major universities and tribal colleges in the State worked together to conceive, design, and implement different STEM-enhancement activities for the tribal college and Reservation high and middle school students ${ }^{6}$. This effort culminated in continued funding from the North Dakota Experimental Program to Stimulate Competitive Research (NDEPSCoR) program of the National Science Foundation since 2004 under the title Nurturing American Tribal Undergraduates in Research and Education (NATURE) http://www.ndsu.edu/epscor/NATURE/research.html. A research component, Tribal College Undergraduate Research Mentoring (TCURMP), was added to NATURE in 2007 as a pilot program. It was later included as a regular component of NATURE ${ }^{7,8}$.

Recent educational research has shown that students who engage in research projects are more likely to enroll in and complete STEM degree programs when compared to other students ${ }^{9}$. Increased understanding of the research process ${ }^{10,11,12}$, a shift from passive to active learning ${ }^{13,14,15}$, enhanced research and laboratory skills ${ }^{10,11,16,17}$, and increased understanding and interest in the discipline are some of the benefits undergraduate students gain by engaging in 
research. Students are also more likely to pursue careers in the STEM field when they had experienced undergraduate research- gains were particularly noticeable among minorities ${ }^{3}$.

Also in the last several years, the tribal colleges have been validating traditional tribal knowledge and exploring scientific concepts from Native perspectives. Embedded in this effort is a deep respect for traditional tribal knowledge and a desire to combine the Western notions of scientific methods and that of Native science concepts in the right proportions in order to create something that is academically rigorous and relevant to the needs of the contemporary tribal societies ${ }^{18}$. Educational research in inquiry-based learning has found that experiential formats (as opposed to textual), particularly within a context of relevance, were more effective as teaching tools for Native American students ${ }^{2}$. This approach was integrated into the tribal college student research mentoring model of the program. The research experience program is set up so that the students have the opportunity to work with two co-mentors, one from a tribal college and the other from a university, working collaboratively through the academic year. Students do research on their respective campuses during the academic year. The expectations are that the university and tribal college faculty mentors would help students to select research topics and develop the appropriate research questions (hypotheses) and advise on techniques/methods of investigation, design of experiments, data analysis, drawing appropriate conclusions, and preparing presentations and reports of their research findings. Imparting research skills is the emphasis and not necessarily discovery research. The titles of student research projects in this program since its inception can be found at the ND EPSCoR NATURE website http://www.ndsu.edu/epscor/NATURE/research.html. Details and implementation procedures of the research mentoring model can be found in Padmanabhan and Davis, 2008 and 2011. The goals of the program include retention of students in STEM areas by offering them research experience opportunities. The collaboration between the tribal college and a mentor from a research institution linked to improving the community with the objective of retaining and nurturing students is the hallmark of this program.

Though some background information on the TCURMP is provided for the context, this paper is not on the TCURMP itself, but on specific student research projects of relevance to the community on radon mitigation completed under this program in Turtle Mountain Community College (TMCC), one of the tribal colleges in the State.

\section{Community-Relevant Radon Research at TMCC}

One of the salient features of the TCURMP is the flexibility the TCC students and faculty have in the selection of any research topic of relevance to their community. Under this program, instructors at TCC were asked to recruit interested students and organize research projects of relevance to the community which would be for duration of one or two semesters. As a result, from 2006 to 2010, a series of student projects were proposed by the TMCC faculty on the topic of radon entrance into residential homes to study: 1) parameters and conditions in homes which had high levels of radon, 2) the feasibility of constructing radon mitigation systems by local 
residents, and 3) the $\mathrm{CO}_{2}$ (radon surrogate) entrance into soil and a model building using sensors. Description of the projects follows:

\section{Project 1}

The first of these projects was "Radon Parameter Study: Investigation of High-Radon Residences on the Turtle Mountain Chippewa Reservation.” A 2003- 2007 prior radon study funded by the Centers for Disease Control (CDC) on the Turtle Mountain Chippewa Reservation established that approximately $25 \%$ of residents tested were over the $4 \mathrm{pCi} / \mathrm{L}$ level cited by the EPA as the "action" level for mitigation, and that another $7 \%$ of residences were over a high-risk level of $10 \mathrm{pCi} / \mathrm{L}$.

Student interns decided to continue to investigate the radon problem on the reservation by looking more closely at high-radon homes (over $8 \mathrm{pCi} / \mathrm{L}$ ) and comparing these to five control homes (less than $4 \mathrm{pCi} / \mathrm{L}$ ) in terms of weatherization level; gas levels $\left(\mathrm{CO}_{2}\right.$ and $\left.\mathrm{O}_{2}\right)$; temperature, humidity and pressure; construction materials and history; and soil permeability. Geological literature was also investigated to assess the overall radon potential of the area.

Weatherization checks were done by students calculating heat dissipation rates with thermal energy equations, while gas levels were checked with CBL (Vernier) gas level probes. Permeability was measured through a two-ring infiltrometer system installed at 4 inches under the surface topsoil with hydraulic heads of $5 \mathrm{~cm}$ in both rings. Students made and installed the infiltrometer systems and timed infiltration rates. Construction materials information and history were obtained by questioning of participants and direct observation. Topography was measured on one side of the residence with a hand-held inclinometer at $50 \mathrm{ft}$.

A literature search for the study showed that potential for high radon existed everywhere due to a relatively high uranium content of bedrock, and high permeability of glacial till. Weatherization appeared to be poor in most residences with high radon, leading to the hypothesis by the study group that construction integrity at all levels was poor, providing an avenue for radon entry and exit, which was necessary for overall flow of radon through the residence. Of interest was the fact that most high-radon residences were built prior to 1980. Only two of the residences were recently built, but showed anomalies such as large expanses of soil exposure (crawl spaces) and probable structural damage due to flooding.

Cultural implications of the study were important as well. There is a tribal tradition of community cooperation to solve problems and student participation in the study strengthened this practice. Many of the participants were elders and were more than willing to help in the study, while students shared knowledge and resources with the participants. The students were interested in continuing the study by installing mitigation systems in selected homes and monitoring radon levels following this. 


\section{Project 2}

The second project in 2007 was titled: "Radon Mitigation System Construction Project Feasibility and Cost Analysis." The prior TCURMP grant project at TMCC in 2006 resulted in establishing the geological background of Rolette County (bedrock, glacial till and soil permeability); high-radon residences were also evaluated individually for ventilation tendencies, construction materials, age, and gas levels. Most high-radon residences, compared to low-radon control residences, were older, more highly ventilated, and had more visible integrity problems, particularly discontinuities of floor and wall structures. Student interns elected to continue the study to include feasibility of constructing radon mitigation structures in several high-radon residences.

Abatement strategies were researched mostly through commercial and homeowner web sites and several plans were considered. Student interns had background knowledge in power tool use and some construction ability, but found it necessary to research abatement strategies closely; subslab depressurization directly through the basement floor or through sump holes was the method decided on and construction of the systems on four houses began in late October 2007. Materials included model RP-145 radon ventilation fans, 4" inlet and 2" outlet PVC piping and rubberized joint sleeves as well as inverted-Y PVC condensation tubing. Electrical outside conduit-covered wiring was extended through standard wiring back into basements for plug-ins into existing basement outlets.

Material and labor costs were compiled, and the process was documented through text and photographs, which eventually may be presented as a feasibility study on a local website. Students concluded that radon remediation as a self-project was indeed feasible, with the help of DIY and commercial web-based tutorials and some mechanical ability (use of power tools). Cost analysis showed that the TMCC study, with use of local materials, resulted in a cost of approximately $\$ 300$ per home for materials. In terms of labor, interns found that approximately 12 man-hours of work were needed for each residence. The local newspaper provided coverage of the project, which garnered community interest not only in the subject of radon, but in mitigation strategies for radon as well as a number of other indoor pollutants. Several of the students noted that community members had asked them technical questions about the mitigation process.

\section{Project 3}

The third project titled "Structural Modeling of Terrestrial Gas Movement into Buildings: Relating Soil Properties and Temperature Effects into Gas Flow Equations", was also concerned indirectly with radon in that the project tested the theory that a temperature differential between a heated building and the surrounding soil would produce increased flow of terrestrial gases (including radon) into the building, dependent upon venting (of varying amount) in the roof. 
Monitoring of terrestrial gas flow into a residential model was accomplished, and data were used to construct a spreadsheet modeling of gas flow.

A residential model (100:1 scale) was set into a $1 \mathrm{~m}^{3}$ soil profile; the soil and basement section of the model were fitted with sensors for temperature, pressure, $\mathrm{CO}_{2}$ concentration and moisture content. The bottom of the soil profile was equipped with perforated tubing to allow $\mathrm{CO}_{2}$ delivery to the soil at large; various concentrations were added and $\mathrm{CO}_{2}$ levels in the basement were monitored. Pressure differential between the soil and the internal environment through a foam gasket set into the soil/basement boundary was calculated and a simple Excel spreadsheet modeling of $\mathrm{CO}_{2}$ inflow was constructed. The model was used to estimate a permeability constant via Darcy's equation.

Further tests were conducted with a rising temperature variable under various venting conditions for the basement, as well as with several soil types of differing moisture content. Natural $\mathrm{CO}_{2}$ in the soil reservoir (and atmosphere) was used as the source of gas. $\mathrm{CO}_{2}$ inflow from the soil was monitored through the soil/basement interface while temperature, pressure and $\mathrm{CO}_{2}$ level in the basement were monitored. The latter experimental data were entered into a somewhat more complex Excel model which simulated $\mathrm{CO}_{2}$ inflow. Constructed inflow curves were based on initial inflow rates as closely as possible and differences in experimental and constructed inflow concentrations were interpreted as outflow concentrations, allowing for evaluation of $\mathrm{CO}_{2}$ outflow according to venting scheme. Diffusivity constants were also estimated via Fick's equation.

Temperature differentials did create increased $\mathrm{CO}_{2}$ concentrations in the basement, which varied by type of soil; however, the range of venting conditions in the study showed no marked difference in slowing or expediting $\mathrm{CO}_{2}$ accumulation in the model basement. Excel model results were also effective at simulating gas inflow and approximating outflow when Darcy's and Fick's equations were adhered to while using experimental $\mathrm{CO}_{2}$ concentration data in the model.

Although of less public visibility, this project helped introduce students to modeling of data, an important approach to applying scientific theory to real phenomena. Student interns presented posters for all three projects at EPSCoR conferences, resulting in newspaper articles on their activities; this helped keep environmental issues in the public eye and also helped community members view themselves as stakeholders in these issues when their own community members engaged in the research, as opposed to outside experts alone.

\section{Benefits of Research Participation to TMCC Students}

- Real-World Science: In actual college-level research, students contribute a part to a complex whole, supervised by faculty that are knowledgeable, rather than testing simplified hypotheses on their own. This allows the students to learn beyond the textbook, and also to experience professional-level research projects and to present their findings at professional conferences. The emphasis at professional university-level 
conferences is one of mentoring, encouragement and academic accountability as opposed to local or intertribal conferences which tend to regard poster and power-point sessions as competitions, usually juried by non-science personnel, where popular interest is a priority over sound conservative research.

- Cultural Relevance: Students typically selected a research subject of interest to them, which usually had some relevance to the community. The reservation community itself is particularly concerned with reservation environmental or infrastructure issues since the reservation is seen as not just a place to live, but as an ancestral homeland designated to them for stewardship, from which they will probably only leave temporarily or not leave at all. North Dakota reservations typically face a number of problems that are common to the rest of the state, but necessarily must be handled by a different governmental entitytribal or federal. There are issues of drought and flood, changing climate parameters, airborne and water pollutants, present or imminent hydraulic fracturing, overflowing landfills, high accident and diabetes rates. Public schools have been evaluated and found lacking according to the NCLB legislation. Tribal administrators must provide the expertise and funding (from limited sources) to face these and many other challenges.

The majority of tribal members see education as a distinct tool for their own people to gain the expertise to handle their own problems. Education is seen as a way of improving the job and economic situation on the reservation, not just in benefitting the person who pursues the education. The local community college is regarded as an important investment in the community, and any research project that comes from it is important in not only raising the level of local expertise, but is perhaps important also in providing some answers to existing problems. In conducting our radon and terrestrial gas studies, students realized that radon was a national and state problem as well as on the reservation, but also that the problem was perhaps exacerbated on the reservation by the lack of any advanced building codes (which also occurs in rural communities in general) as well as by the lack of income to hire outside companies to prevent or mitigate radon problems. In this case, education and research allowed them to determine it could be done by locals and in a cost-effective manner.

- Exposure to Research Protocol: Students were asked to do literature searches, which they had rarely done previously, and they were able to do this with some supervision- as a group we looked at various sources and selected articles by the relevance to our study. Interns quickly learned that eliminating sources was more of a problem than finding information and that website credentials were important.

The faculty PI at the college usually outlined the proposal and assigned students various tasks- often the students and PI met as a group and planned the most efficient way to 
accomplish tasks and rough out a time-line of the study. Most students reiterated that these studies were much longer than any previous study they had undertaken in the past and that they had not worked before in a collaborative effort. The students were also able to note that planning and execution followed distinct stages- literature search, experimental design, data collection and evaluation, and drawing of conclusions.

Exposure to technical writing was invaluable for most of the students- although writing skills are poor across the board in the U.S., scores are particularly low at TCCs. Science and math scores on assessment tests such as the Praxis (for secondary education students) are moderately lower than national medians, but English skills are very much lower. In conducting studies at TMCC, the mentors and students discussed what should be included in a poster or report. The students submitted written data reports and the mentor showed the students how their narratives were expanded to a poster and a full report. The students were required to proofread the poster and final report and suggest changes or additions. Several students in these projects stated that the model of technical writing helped them with composing college papers in their coursework.

- Exposure to Technology: When data were collected, all of the interns were able to use a variety of scientific instrumentation, most of which they had not previously encountered. In the research projects completed in the past seven years at TMCC, students have used the atomic absorption spectrophotometer, gas chromatograph/mass spectrometer, graphite furnace, bomb calorimeter and UV/VIS spectrophotometer for various purposes, giving them research opportunities at least partially on a par with what they would encounter at a larger university. In the above series of radon studies, as well as in a number of other studies, a large variety of educational sensors and kits were used, with which students had only limited experience. Most of the students had little or no experience with modeling of data in Excel, in statistical evaluation of data, or even in generating graphs for interpretation of trends in data. Gaining experience in these areas is important in placing the TMCC students near the same level as students with broader high school or collegiate experiences.

- Research as Coursework Reinforcement: Students who worked with faculty as mentors were probably surprised to note that these faculty members were working scientists, not just tiresome taskmasters lecturing endlessly at the podium and handing out mounds of tedious homework. They saw a different side of science- professionals seeking answers to real problems, and using their knowledge to that end. Homework that had seemed meaningless now was used to calculate actual results; concepts that were memorized to pass a test now had real application. "Inquiry" approach in teaching has been shown to be quite effective in not only retaining student interest, but in reinforcing educational concepts through application. Researchers have found that this approach increases not 
only literacy, critical skills and conceptual understanding, but some intangibles which may be more lasting: the value of intrinsic rewards, positive view of science, and validation of student contribution ${ }^{2,4}$.

However, most college instructors are restricted by the laundry list of competencies that must be covered during a semester, so that inquiry investigations realistically occur only in once-a-week laboratories. Programs that promote smaller scale research which can engage more than one student at a time are very important in that they can increase the "inquiry" aspect of education when time (and funding) constraints make it hard to incorporate this into the traditional coursework scheme. The only drawback of programs like this is that the programs cannot be expanded to include more students and more parttime faculty to conduct more projects.

\section{Impact of TCURMP on TCC Research Capacity}

Faculty Enhancement: The series of TCURMP research projects have provided increasing research opportunities for students at TMCC over the past several years. An advantage of the TCURMP is that full-time faculty at tribal colleges do not have to be the sole experts on the research topics for mentoring students. Faculty from research universities can provide assistance for mentoring students in their area of expertise. Faculty members at tribal colleges are typically generalists, who are valued more for their ability to teach in several discipline areas, rather than for possessing a specialized research focus. A number of faculty members do possess master's or doctorate degrees with research theses or dissertations, but usually teach full-time and conduct research as a part-time pursuit. There are also a fair number of faculty that have science education master's or doctorate degrees, which do not usually involve research theses or dissertations in a science discipline. An advantage of TCURMP has been the presence of a university mentor with expertise appropriate to the student research, who can help not only students but community college faculty increase their research skills and subject knowledge in the study of choice. This is a unique situation that affords a higher level of research than might otherwise be produced at the two-year institutions as well as training for TMCC faculty for future applications.

Funding sources: Funding for research projects at TMCC have increased substantially with the advent of EPSCoR several years ago. Large governmental foundations such as NSF and NIH have been more likely to fund educational programs than research projects aimed at college undergraduates. TCURMP is unique in that there is a wide range of possible project choices for students, and the studies are more short-term, allowing more students to participate over the same time frame as a longer study would allow.

Instrumentation: Equipment and instrumentation have been obtained through a number of grants. For example, within the last seven years, the chemistry department has gone from possessing only a used atomic absorption spectrophotometer and 10-year old ECD gas chromatograph to 
accumulating a newer model AA spectrophotometer, a graphite furnace, an IR spectrophotometer, a UV spectrophotometer, a high-performance liquid chromatograph, mass spectrometer/gas chromatograph, and a micro solid/liquid bomb calorimeter. These additions to the research capacity at TMCC have been very helpful in carrying out not only NATURE student research projects, which have little extra funding for equipment, but a number of other grant studies through various agencies such as the EPA and NASA.

Sustainability: Networking with university experts has not only helped establish TMCC research capability but has continued to be a major influence in sustaining and increasing that growth. A number of university graduate students have been recruited by their professors at the two major research universities in North Dakota to write proposals to fund their outreach activities at community colleges, with very beneficial results. This has been a direct outcome of the TCURMP in particular. Through EPSCoR and other funding agencies, faculty here expect to be able to collaborate with university personnel on more capacity-building projects in the next decade.

\section{Assessment of Student Experience}

The National Science Foundation (NSF) has directed that a number of programs, including EPSCoR, promote science progress nationwide. Progress includes partnering between government, higher education, and industry to establish sustainable research infrastructure. The TCURMP program, as part of EPSCoR, is meant to help Native American tribal colleges build or expand programs which promote student attainment of STEM careers. Though the wording is general, the promotion of STEM learning must take place through course offerings or reinforcement of course principles through various means such as research, seminars, tutoring in some capacity, and workshops or other innovative means. Cultivation of values, attitudes and orientation geared toward recognizing the worth of working in a STEM career field is concomitantly accomplished through networking, collaboration, example, encouragement and demonstrated importance of outcomes, particularly in research. A poster, presentation or publication is an important tool in convincing students that they have worked on solving a problem of some import and that their effort is appreciated by peers and the community.

Twelve student interns have conducted TCURMP projects at TMCC since 2007. Of these, three are presently continuing their education at TMCC; one of them is scheduled to enter the Food Science Program at North Dakota state University next year, one is in the Secondary Science Education Program at TMCC, while the third is working as an EMT at the local hospital while he accumulates more credits toward a health science degree.

Nine students out of the original twelve have obtained their associate's degree at TMCC and moved on to higher level education or obtained jobs. One of these now works for the Tribal EPA Office on the reservation. Three of the graduates attained bachelor's degrees in the Secondary Science Education Program and are now teaching. One of the student interns is 
attending North Dakota State University, while another works in the construction trade and occasionally advises homeowners about radon mitigation systems. Three former interns are attending the University of North Dakota - one in general studies, one in pre-medicine and one in pre-dentistry.

In general, a limited number of TMCC students who start out at the college graduate with an associate degree. In 2009, 19.5\% of the students who started out in 2007 graduated, and in 2011 $10.6 \%$ graduated. This is below the national rate of about $28 \%$. An even smaller percentage of these students go on to four-year degrees. However, amongst former student interns of the TCURMP, graduation was $100 \%$ and advancement (or planned advancement) into a STEM fouryear program, including the Secondary Science Education Program at TMCC, was nearly 100\%. On a larger scale, all 40 students who engaged in any research at TMCC from 2005 to summer 2011 , had a graduation rate of $80 \%$. In terms of employment, $65 \%$ of the original 40 are known to be employed, $8 \%$ are still in school and $28 \%$ have not been tracked successfully, but probably are employed outside the immediate community. Out of those known to be employed, $77 \%$ are employed in a STEM field, while the remaining $23 \%$ are employed in non -STEM jobs. These statistics are retained by the director of a TCUP Grant at TMCC, who follows up on research students who participate in tracking, as well as the EPSCoR director at the TMCC campus.

Statistically, students who engaged in undergraduate research at TMCC had significantly higher graduation rates $(80 \%)$ than students in general (10.6\% in 2011). Employment rates also appear to be high for those engaged in research, although comparison is difficult since there is no data for the general student population once they leave the college. These results are to be commended, but the task of the TCURMP program is to retain and assist students in STEM educational fields, with the end objective of these students attaining a STEM four-year degree, which is considered to be the prerequisite to a STEM career. Clearly, from the figures above, retention of students in STEM education who also did TCURMP undergraduate research, after completing a two-year degree, was very successful (close to 100\%). Out of STEM students attending physics and chemistry classes in fall and spring semesters of 2012, the percentage of students who did not engage in undergraduate research and who continued in STEM education after a two-year degree was approximately 50\%, while all those who had engaged in research for that year continued onto four-year educations in STEM fields. The percentage of these students in the entire college and for other years has not been compiled, but may be even less since physics and chemistry students have a higher tendency to graduate than students in general. Although successive years should be closely monitored, at this point assessment of the student experience does show successful alignment with the goals of the TCURMP program.

There may be some merit to the argument that motivated, successful students are the ones most likely to enter a research program; however, although some of the students undeniably fit this description, this set of circumstances is not always the case. Anecdotally, in a number of projects, student interns cited a stipend as being the main motivating factor for them. Additionally, some students regretted not being able to do the research because of heavy 
academic loads or the need to devote all their time to study. The recruitment of the students was thus somewhat random and a good cross-section of students was represented. It is probably logical to assume that retention rates for all students in STEM fields would be higher if research opportunities had been more widespread, since the retention rate for those who did participate was very high.

\section{References}

1. American Association of Community Colleges. 2011. Enrollment Growth at Community Colleges Begins to Ebb. Community College Times. Retrieved Dec 2012 from http://www.communitycollegetimes.com/Pages/Campus-Issues/cc-enrollments.aspx

2. Haury, David L. 1993. Teaching Science through Inquiry. Retrieved Dec 2012 from http://www.gpo.gov/fdsys/pkg/ERIC-ED465545/pdf/ERIC-ED465545.pdf

3. Lopatto, David. 2007. Undergraduate Research Experiences Support Career Decisions and Active Learning. CBE Life Science Education 2007 Winter; 6(4): 297-306. Retrieved Dec 2012 from http://www.ncbi.nlm.nih.gov/pmc/articles/PMC2104507/

4. Vega, Vanessa. 2012. Project-Based Learning Research Review. Edutopia. Retrieved Dec 2012 from http://www.edutopia.org/pbl-research-learning-outcomes

5. Webb, Sarah. 2007. The Importance of Undergraduate Research. Science Careers (Science). Retrieved Dec 2012 from http://sciencecareers.sciencemag.org/career_development/previous_issues/articles/2007_07_06/caredit_a07 $\underline{00095}$

6. Padmanabhan G., Pieri, R. V., and Davis, C. A. and. 2011. A Unique University-Tribal College Collaboration to Strengthen Native American Pathways to STEM Education, AC 2011-184, Proc. of the American Society for Engineering Education Annual Conference, Vancouver, Canada, 2011

7. Padmanabhan G. and Davis, C. A. 2011. Collaborative Research-Mentoring for Tribal College Students, AC 2011-185, Proc. of the American Society for Engineering Education Annual Conference, Vancouver, Canada, 2011

8. Padmanabhan, G. and Davis, C. A. 2008. Undergraduate Research Experience: A Collaborative Model for Tribal Community College Students, GC 2008-133, 7th Global Colloquium on Engineering Education, Cape Town, South Africa, Oct. 19-23.

9. Peterson, M., Kraus, B. \& Windham, T., 2005. Striving toward equity: Underrepresented minorities and mathematics. Society for Industrial and Applied Math, 38(3), Retrieved January 10, 2011, from SIAM: http://www.siam.org/news/news.php?id=50.

10. Alexander, B. B., Foertsch, J. A., \& Daffinrud, S.,1998. Spend a Summer with a Scientist program: An evaluation of program outcomes and the essential elements of success. Madison, WI: University of Wisconsin-Madison, LEAD Center.

11. Foertsch, J. A., Alexander, B. B., \& Penberthy, D. L.,1997. Evaluation of the UW-Madison's Summer Undergraduate Research Programs: Final Report. Madison, WI: University of Wisconsin, Madison, LEAD Center.

12. Alexander, B. B., Lyons, L., Pasch, J. E., \& Patterson, J.,1996. Team Approach in the First Research Experience for Undergraduates in Botany/Zoology 152: Evaluation report. Madison WI: University of Wisconsin-Madison, LEAD Center.

13. Chaplin, S. B., Manske, J. M., \& Cruise, J. L., 1998. Introducing Freshmen to Investigative Research—A Course for Biology Majors at Minnesota's University of St. Thomas. Journal of College Science Teaching, 27(5), 347-350. 
14. Nikolova Eddins, S. G., \& Williams, D. F., 1997. Research-based Learning for Undergraduates: A Model for Merger of Research and Undergraduate Education. Journal on Excellence in College Teaching, 8(3):7794.

15. Schamel, G \& Ayres, M., 1992. The Minds-on Approach: Student Creativity and Personality Involvement in the Undergraduate Science Laboratory. Journal of College Science Teaching, 21(4), 226-229.

16. Kremmer, J. F., \& Bringle, R. G., 2000. The Effects of an Intensive Research Experience on the Careers of Talented Undergraduates. Journal of Research and Development in Education, 24(1), 1-5.

17. Kardash, C. M., 2000. Evaluation of an Undergraduate Research Experience: Perceptions of Undergraduate Interns and their Faculty Mentors. Journal of Educational Psychology, 92(1), 191-201.

18. Boyer, Paul (Ed), 2010. Ancient Wisdom, Modern Science: The Integration of Native Knowledge in Math and Science at Tribally Controlled Colleges and Universities, Published by Salish Kootenai College Press, Pablo, Montana and Distributed by University of Nebraska Press, Lincoln, Nebraska. 